\section{Network Approach for Prevention of Healthcare-Associated Infections}

To the Editor-We applaud the successful reduction of healthcare-associated infection (HAI) rates achieved by hospitals that participated for 5 years or more in the Duke Infection Control Outreach Network (DICON), as described by Anderson and colleagues in their recent report. ${ }^{1}$ DICON provides a successful example of HAI reduction, using validated, risk-adjusted local data to drive prevention activities, and it adds to existing evidence supporting this HAI prevention strategy. ${ }^{2-4}$ To help ensure an accurate understanding of the current landscape of HAI-reporting infrastructures that can contribute to such reductions, we would like to clarify that the National Healthcare Safety Network (NHSN) can, and in some states does, also function much as DICON does to provide complete, validated, risk-adjusted data for local action, with the distinction that funding for NHSN and, particularly, validation requires public support, whereas DICON is funded directly by the facilities it serves. We disagree with the authors' statement that NHSN data are "obtained from convenience samples (ie, are not complete), are not validated, and are not fed back to individual hospitals in a timely fashion," for the following reasons. While it is true that not all US hospitals report HAIs to NHSN and participation in NHSN is still voluntary in some states, increasingly it is being used as a platform for state mandatory reporting of HAIs (23 states and the District of Columbia as of July 2011). Also, beginning in January 2011, NHSN became the reporting tool for central line-associated bloodstream infections in hospitals with intensive care units that participate in the Hospital Inpatient Quality Reporting Program of the Centers for Medicare and Medicaid Services (CMS). ${ }^{5}$ The result is that now more than 4,200 of the 5,800 hospitals in the United States belong to NHSN and are reporting data continuously on a variety of HAIs, with central line-associated bloodstream infections and surgical site infections being the most common focus of surveillance and reporting. Therefore, we believe that as currently constituted, NHSN has become representative of US hospitals for certain HAI types, and future expansion is likely.

Second, validation of NHSN data is an ongoing challenge; however, as a result of the need to assure data quality under state reporting mandates and the general increased use of NHSN nationally, numerous state-based validation efforts have been undertaken since 2007. Initially, some states leveraged existing public health resources or secured state funding for HAI validation; later, under the 2009 American Recovery and Reinvestment Act, the Centers for Disease Control and Prevention (CDC) funded many state HAI programs to audit and validate HAI data. As of May 2011, at least 15 states have conducted audit/validation activities, with published validation reports from Connecticut, ${ }^{6}$ Maryland, ${ }^{7}$ New York, ${ }^{8}$ and Tennessee. ${ }^{9,10}$ Several more states have validation plans for certain NHSN-reported data that are required under state statute. In addition, CMS plans to validate the data reported through NHSN to its Hospital Inpatient Quality Reporting Program. Finally, the NHSN Internet-based application does not allow for the saving of incomplete records, and it subjects the data to numerous cross-field edit checks to assure that criteria are met and nonsensical data are not submitted. The application includes 8 data quality reports that we recommend facilities run monthly. Later this year the application will be enhanced to detect and display, for correction or confirmation, missing denominator data when $\mathrm{HAI}$ event data are reported and missing HAI event data when denominator data are reported.

Third, and most importantly, feedback of comparative data alongside a facility's own data has been a hallmark of NHSN. Facility-specific data are immediately available for analysis by facility staff and anyone allowed by the facility administrator to access the facility's data (ie, through NHSN's group feature). The analysis is most simply performed within the NHSN application with a few clicks of the mouse, and it does not require comparisons of entered data to be processed separately by other analytic software packages. Output options can easily be run, modified, and saved by novice or experienced users to provide both tabular and graphical displays. In addition, as of October 2010, output consistent with the US Department of Health and Human Services' Action Plan Targets and Metrics ${ }^{11}$ was incorporated into the list of NHSN's standard comparative output. Basic analysis training using NHSN is available on the NHSN Web site, ${ }^{12}$ as is a special edition of the NHSN newsletter devoted to the standardized infection ratio metric. ${ }^{13}$ In addition, CDC has offered handson analysis training courses at the past 2 Society for Healthcare Epidemiology of America annual conferences and 2 recent national webinars sponsored by the Association for Professionals in Infection Control and Epidemiology to facilitate the use and interpretation of analytical output.

The analysis tables with comparative NHSN data are displayed next to the facility's own data and include $P$ values, confidence intervals, and percentile rankings that help the infection preventionist and the hospital epidemiologist understand where they may need to focus their prevention efforts. However, we understand that data tables alone are not sufficient to drive change, and so we have funded states to develop HAI prevention capacity. These state-based programs are beginning to function much as DICON does, but without cost to the facilities. In addition, CMS funds state-based quality improvement organizations to do much the same thing for those measures included in its Hospital Inpatient Quality 
Reporting Program. CDC will continue to provide tools for these patient safety efforts, and NHSN will evolve to help reduce the burden of data collection and inconsistencies between data collectors.

\section{ACKNOWLEDGMENTS}

Potential conflicts of interest. All authors report no conflicts of interest relevant to this article.

Teresa C. Horan, MPH; ${ }^{1}$ Kathryn E. Arnold, MD; ${ }^{1}$ Catherine A. Rebmann, MPH; ${ }^{1}$ Scott K. Fridkin, MD $^{1}$

Affiliations: 1. Division of Healthcare Quality Promotion, National Center for Emerging and Zoonotic Infectious Diseases, Centers for Disease Control and Prevention, Atlanta, Georgia.

Address correspondence to Teresa C. Horan, MPH, Division of Healthcare Quality Promotion, National Center for Emerging and Zoonotic Infectious Diseases, Centers for Disease Control and Prevention, Mailstop A-24, 1600 Clifton Road NE, Atlanta, GA 30333 (thoran@cdc.gov).

The findings and conclusions in this letter are those of the author(s) and do not necessarily represent the official position of the Centers for Disease Control and Prevention.

Infect Control Hosp Epidemiol 2011;32(11):1143-1144

(C) 2011 by The Society for Healthcare Epidemiology of America. All rights reserved. 0899-823X/2011/3211-0018\$15.00. DOI: 10.1086/662588

\section{REFERENCES}

1. Anderson DJ, Miller BA, Chen LF, et al. The network approach for prevention of healthcare-associated infections: long-term effect of participation in the duke infection control outreach network. Infect Control Hosp Epidemiol 2011;32(4):315-322.

2. Burton DC, Edwards JR, Horan TC, Jernigan JA, Fridkin SK. Methicillin-resistant Staphylococcus aureus central lineassociated bloodstream infections in US intensive care units, 1997-2007. JAMA 2009;301(7):727-736.

3. Centers for Disease Control and Prevention. Reduction in central line-associated bloodstream infections among patients in intensive care units: Pennsylvania, April 2001-March 2005. Morb Mortal Wkly Rep 2005;54(40):1013-1016.

4. Centers for Disease Control and Prevention. Vital signs: central line-associated blood stream infections: United States, 2001, 2008, and 2009. Morb Mortal Wkly Rep 2011;60(8):243-248.

5. Centers for Medicare and Medicaid Services. Hospital inpatient quality reporting program. Centers for Medicare and Medicaid Services Web site. http://www.cms.gov/HospitalQualityInits/08 _HospitalRHQDAPU.asp. Accessed May 3, 2011.

6. Backman LA, Melchreit R, Rodriguez R. Validation of the surveillance and reporting of central line-associated bloodstream infection data to a state health department. Am J Infect Control 2010;38:832-838.

7. Maryland Health Care Commission. Central line-associated blood stream infections: data quality review and chart audit, June 2010. Maryland Health Care Commission Web site. http:// mhcc.maryland.gov/healthcare_associated_infections/hai/clabsi _final_rpt_20100618.pdf. Published 2010. Accessed May 19, 2011.

8. New York State Department of Health. Hospital-acquired infection reporting system pilot year: 2007. New York State Department of Health Web site. http://www.health.ny.gov/statistics/facilities/ hospital/hospital_acquired_infections/2007/docs/hospitalacquired_infection-full_report.pdf. Published June 30, 2008. Accessed May 19, 2011.

9. Soe MM, Kainer MA. Sustainable, cost-effective internal data validation of healthcare associated infections surveillance reported to the National Healthcare Safety Network [NHSN]. In: Final Program of the 5th Decennial International Conference on Healthcare-Associated Infections: Atlanta, GA: March 18-22, 2010. Abstract 81.

10. Kainer MA, Mitchell J, Frost BA, Soe MM. Validation of central line associated blood stream infection [CLABSI] data submitted to the National Healthcare Safety Network [NHSN]: a pilot study by the Tennessee Department of Health [TDH]. In: Final Program of the 5th Decennial International Conference on Healthcare-Associated Infections: Atlanta, GA: March 18-22, 2010. Abstract 456.

11. US Department of Health and Human Services. HHS action plan to prevent healthcare-associated infections. US Department of Health and Human Services Web site. http:/www.hhs.gov/ ash/initiatives/hai/actionplan/index.html. Accessed May 3, 2011.

12. Centers for Disease Control and Prevention. NHSN training. Centers for Disease Control and Prevention Web site. http:// www.cdc.gov/nhsn/training.html. Published 2006. Accessed May 3, 2011.

13. Centers for Disease Control and Prevention. NHSN newsletters. Centers for Disease Control and Prevention Web site. http:// www.cdc.gov/nhsn/PDFs/Newsletters/NHSN_NL_OCT _2010SE_final.pdf. Accessed May 3, 2011.

\section{Intolerance of Chlorhexidine as a Skin Antiseptic in Patients Undergoing Hemodialysis}

To the Editor-Bloodstream infections. (BSIs) are an important problem among patients undergoing hemodialysis. Current estimates suggest that there were about 37,000 accessrelated BSIs among hemodialysis patients with central lines in 2008. ${ }^{1}$ This number is similar to the estimated 41,000 central line-associated BSIs that occurred in all US hospital patients in 2009. In addition, rates of hospitalization for bacteremia/septicemia have increased $47 \%$ among hemodialysis patients from 1993 to $2008 .^{2}$ A number of interventions have been recommended to prevent access-related BSIs, particularly among patients who have central lines. One important recommendation is the use of chlorhexidine gluconate $(>0.5 \%)$ with alcohol as the first-line skin antiseptic for routine care of central line insertion sites, on the basis of evidence that it is superior to alternative antiseptics. ${ }^{3}$ Further, $2 \%$ chlorhexidine with $70 \%$ alcohol is also recommended by the National Kidney Foundation's Kidney Disease Outcomes Quality Initiative as 1 of 3 options for skin antisepsis for subcutaneous arteriovenous (AV) access. ${ }^{4}$

Chlorhexidine appears to be generally well tolerated. There 